\title{
Research on the Voltage Stability of Grid Connected Wind Farm Based on STATCOM Technology
}

\author{
Haolin Zhang ${ }^{1,2}$, Lingyun Wang ${ }^{1,2, *}$, Jiaxing $\operatorname{Sun}^{1}$ and Xingyuan $\mathrm{Hu}^{1}$ \\ ${ }^{1}$ College of Electrical Engineering and New Energy, China Three Gorges University, Yichang, 443002, China \\ ${ }^{2}$ Hubei Provincial Collaborative Innovation Center for New Energy Microgrid, Yichang, 443002, China \\ *Corresponding author
}

\begin{abstract}
Nowadays variable speed constant frequency (VSCF) wind power generation system is adopted in the most wind farms. Its parallel operational characteristics will affect the voltage stability of the power grid. Based on the modeling method of the lumped wind farms, the grid connected wind farm simulation model is set up. The voltage stability problem of the grid connected wind farm can be solved by integrating STATCOM on the terminal of wind farm in parallel. Then, the voltage stability is analyzed according to different disturbance patterns. Meanwhile, the method of integrating capacitors with the power grid in parallel is also compared. The results show that it is effective to improve the voltage stability of grid connected wind farms by using STATCOM.
\end{abstract}

Keywords-wind farm; wind turbines; reactive power compensation; STATCOM

\section{INTRODUCTION}

Nowadays wind power technology is developing rapidly, new wind turbines have made great progress than before, and their negative effects on wind grid parallel operation have been reduced[1]. However, VSCF doubly-fed induction generator is used widely in wind farm, which has become the most popular type of turbine. In Ref [2], reactive power control and voltage stability is investigated for doubly-fed wind farm. In Ref [3], the control strategy and characteristic of doubly-fed induction generators studied and the mathematic model of dynamic stability for induction generator is also introduced.

Rapid development of modern power electronics technology makes static reactive power compensator widely used to improve voltage quality and stability of the system. Starting from learning the working principle of SVC, the research is done about enhancing the stability of induction motor by simulation. Generally, the compensation effect of SVC is mainly determined by voltage. In other words, based on the operating principle of SVC, when the voltage of external power grid becomes lower, the compensated voltage may not be as good as rated voltage. It is found that the wind farm transient voltage stability of constant speed wind turbine and wound induction generator can be improved by STATCOM, it can effectively help wind farm recover voltage after power grid fault and improve the low voltage ride through capability of wind farms, however, the influences of voltage stability cause by variable forms of wind is not considered [6]. In Ref [7], the STATCOM is cascaded to the outlet position of the wind farm to improve the voltage stability and improve the fault recovery ability of the wind farm. In Ref [8], it is proposed to control the use of different modulation modes based on cascaded $\mathrm{H}$ bridge multilevel circuit STATCOM, the compensation characteristics of STATCOM is analyzed when the voltage drops steeply. The results show that the proposed method can effectively compensate the reactive power of the wind farm and improve the low voltage ride through capability and the voltage stability of the wind farm.

Based on the analysis of the above researches, the influence of STATCOM on the voltage stability of grid connected wind farm is not taken into account. In this paper, the influence of STATCOM on the voltage stability of the system is studied based on the grid connected wind farm and the STATCOM device is connected to the outlet of the wind farm. It is expected that this method will play an important role in the study of voltage stability of grid connected wind farm.

\section{STABILITY ANALYSIS OF GRID-CONNECTED WIND FARM}

In power system, the voltage is closely related to the reactive power compensation. Although appearance of new wind power generator makes the reactive power compensation no longer a crucial factor of voltage stability. At present, VSCF wind turbine including doubly-fed induction generator is one of the most popular turbines in wind farms, it will absorb reactive power from the grid meanwhile it will generate active power. Because of the asynchronous generator cannot control dynamic reactive power, the demand of reactive power is supported by power grid. Therefore, reactive power compensation still plays an important role in voltage stability when there is a large disturbance.

\section{A. Static Reactive Power Compensation System}

STATCOM is a kind of reactive power compensation device. When there is a fault in the external power grid, the response of the wind farm is generally adjusting the turbine speed faster, dropping down the voltage and absorbing more reactive power. If STATCOM is used to adjust reactive power rapidly, recover wind turbine terminal voltage and keep the turbine speed in a reasonable range, the wind farm voltage can be kept stably.

The equivalent circuit model of STATCOM is expressed as:

$$
L \frac{d i_{s}}{d t}=-R i_{s}+u_{s}-u_{c}
$$


where $i_{\mathrm{s}}$ is the system current, $u_{\mathrm{s}}$ is the system voltage, $u_{\mathrm{c}}$ is the output voltage of STATCOM, $L$ is reactance, $R$ is the total resistance of linked reactance and STATCOM. In order to control the system power effectively, and guarantee the better response characteristic of reactive current, Park transformation is adopted to calculate the system power. The circuit equation of DC link can be obtained by the balanced power. Then, the mathematic model of STATCOM based on instantaneous power can be expressed as

$$
\frac{d}{d t}\left[\begin{array}{c}
i_{d} \\
i_{q} \\
u_{d c}
\end{array}\right]=\left[\begin{array}{ccc}
-\frac{R}{L} & \omega & -\frac{\sqrt{3} K}{\sqrt{2} L} \sin \delta \\
-\omega & -\frac{R}{L} & -\frac{\sqrt{3} K}{\sqrt{2} L} \cos \delta \\
\frac{\sqrt{3} K}{\sqrt{2} C} \sin \delta & \frac{\sqrt{3} K}{\sqrt{2} C} \cos \delta & 0
\end{array}\right]\left[\begin{array}{c}
i_{d} \\
i_{q} \\
u_{d c}
\end{array}\right]+\frac{1}{L}\left[\begin{array}{c}
0 \\
\sqrt{3} u_{s} \\
0
\end{array}\right]
$$

where $K$ is the proportional gain for STATCOM, $\delta$ is the angle between STATCOM output voltage and the system voltage at the synchronous signal sampling point, $\omega$ is the rotational angular frequency in d-q coordinate, $u_{\mathrm{s}}$ is the RMS value of instantaneous system voltage, $u_{\mathrm{dc}}$ is the capacitor voltage at the DC link and $C$ is capacitance. According to instantaneous power theory, when STATCOM is connected into the power system, the instantaneous three-phase active power and reactive power are:

$$
\left\{\begin{array}{l}
p(t)=u_{d}(t) i_{d}(t)+u_{q}(t) i_{q}(t) \\
q(t)=u_{q}(t) i_{d}(t)-u_{d}(t) i_{q}(t)
\end{array}\right.
$$

meanwhile, $u_{\mathrm{d}}=0, u_{\mathrm{q}}=-\sqrt{3} u_{\mathrm{s}}$,

Then,

$$
\left\{\begin{array}{l}
p(t)=-\sqrt{3} u_{s} i_{q}(t) \\
q(t)=-\sqrt{3} u_{s} i_{d}(t)
\end{array}\right.
$$

From the above statement, according to the reactive power and active power of the system, properly adjusting the amplitude and phase of each bridge circuit of AC side output voltage or directly control the AC side current can make the circuit absorb or deliver the reactive current which satisfies the requirement of system, therefore, dynamic reactive power compensation is realized.

\section{MATHEMATICAL MODEL ANALYSIS OF GRID-CONNECTED WIND FARM}

It is necessary to establish a reasonable mathematical model to analyze the dynamic characteristics of the wind power system. The establishment of mathematical model is related to the object and the requirement of simulation precision. In this paper, VSCF wind power generation system is investigated and its grid connection operational characteristic is analyzed.

\section{A. Mathematical Model of Doubly-Fed Induction Generator}

In this paper, the mathematical model of doubly-fed induction generator is set up in the two-phase synchronous rotating coordinate system. The doubly-fed induction wind generator stator is connected directly to the grid, so the voltage fluctuation is relatively smooth. In the study of electromechanical transient problem of doubly-fed induction wind generator under parallel operation, the dynamic process of stator winding loop can be ignored. Then, the stator voltage equations become:

$$
\left\{\begin{array}{l}
U_{s d}=R_{s}\left(-I_{s d}\right)-\omega_{1} L_{s}\left(-I_{s q}\right)+E_{d} \\
U_{s q}=R_{s}\left(-I_{s q}\right)+\omega_{1} L_{s}\left(-I_{s d}\right)+E_{q}
\end{array}\right.
$$

where $U_{\text {sd }}, U_{\text {sq }}$ are d-axis and q-axis component of the stator voltage, $R_{\mathrm{S}}, R_{\mathrm{r}}$ are stator and rotor winding resistance respectively, $L_{\mathrm{S}}$ 'is the transient inductance of stator winding, $L_{\mathrm{S}}$ $=\left(L_{\mathrm{s}}-L_{\mathrm{m}}\right) / L_{\mathrm{r}} . \omega_{1}$ is the synchronous rotational angular speed, $\omega_{\mathrm{r}}$ is the rotor rotational angular speed, $s$ is slip ratio, $s=\left(\omega_{1}-\omega_{\mathrm{r}}\right) / \omega_{1}, \quad E_{\mathrm{d}}$ and $E_{\mathrm{q}}$ are respectively the $\mathrm{d}-\mathrm{q}$ axis components of doubly-fed induction generator stator electromotive force.

Substituting the rotor flux linkage equation into the rotor voltage equation and eliminating rotor current in the rotor voltage equations, the operational principle of internal electromotive force is as follows:

$$
\left\{\begin{array}{l}
\frac{d E_{d}}{d t}=-\frac{R_{r}}{L_{r}}\left[E_{d}-\omega_{1}\left(L_{s}-L_{s}^{\prime}\right) I_{s q}\right]+s \omega_{1} E_{q}-\frac{L_{m}}{L_{r}} \omega_{1} U_{r q} \\
\frac{d E_{q}}{d t}=-\frac{R_{r}}{L_{r}}\left[E_{q}+\omega_{1}\left(L_{s}-L_{s}^{\prime}\right) I_{s d}\right]-s \omega_{1} E_{d}+\frac{L_{m}}{L_{r}} \omega_{1} U_{r d}
\end{array}\right.
$$

where $U_{\mathrm{rd}}, U_{\mathrm{rq}}$ are d-axis and q-axis component of the rotor voltage, $L_{\mathrm{s}}, L_{\mathrm{r}}$ are the d-q axis equivalent self- inductance of the stator and rotor respectively, $L_{\mathrm{m}}$ is the excitation inductance of equivalent winding, $I_{\mathrm{rd}}, I_{\mathrm{rq}}$ are the d-q axis component of rotor current respectively. Based on the above equations, the three-order dynamic model of doubly-fed induction generator is established.

\section{SiMULATION ANALYSIS OF INFLUENCE OF STATCOM ON Voltage STABILITY OF Wind FARM}

\section{A. Simulation Model of 50MW Wind Farm}

The wind power generator is connected to $110 \mathrm{kV}$ power grid through a step-up transformer. The installed capacity of wind farm is 50MW. Assume that wind power generator and step-up transformer have the same capacity. Short-circuit voltage $\quad u \%=10.5$, reactance $X=0.105 \mathrm{p} . \mathrm{u}, \quad$ resistance $R=0.000525$ p.u. The simulation model of grid-connected wind farm is shown in Figure 1: 


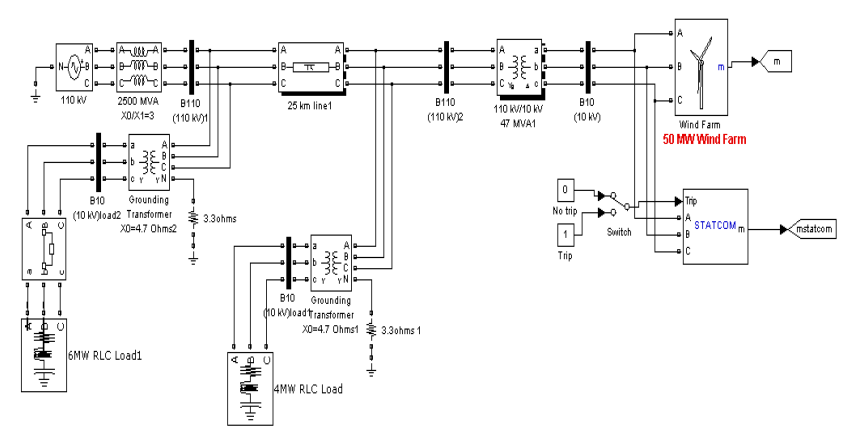

FIGURE I. SIMULATION MODEL OF GRID-CONNECTED WIND FARM

\section{B. Simulation Case under Gust Wind Disturbance}

In the analysis of transient voltage stability of wind farm, gust wind is one of the biggest threat to voltage stability of wind farm. Therefore, it is crucial to study the effect of STATCOM on voltage stability of wind farms under the gust wind.

1) Simulation analysis of capacitor compensation and static synchronous reactive power compensation under the case of same intensity gust wind and different time period.

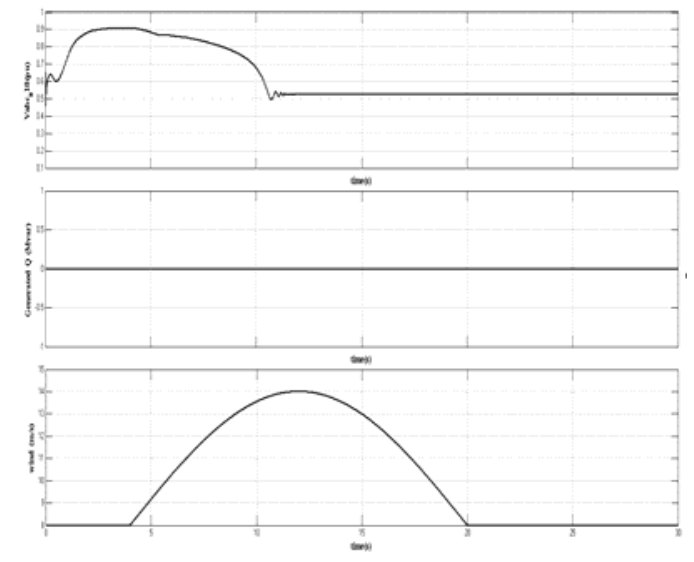

FIGURE II. WAVEFORM OF CAPACITOR COMPENSATION

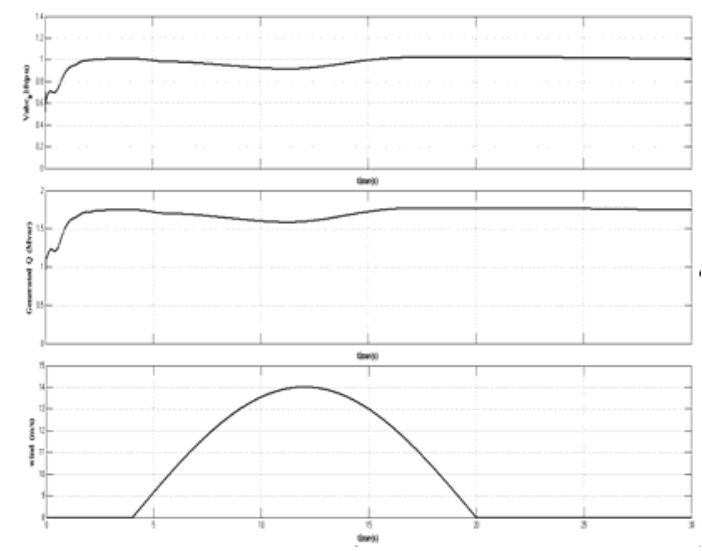

FIGURE III. WAVEFORM OF STATCOM COMPENSATION

Figure 2-3 are the simulation results under ideal condition, where the average wind speed is $8 \mathrm{~m} / \mathrm{s}$, gust wind strength is
$5.4 \mathrm{~m} / \mathrm{s}$ and action time is $16 \mathrm{~s}$. The voltage measuring point is on $10 \mathrm{kV}$ line of high voltage side of wind farm. The voltage waveforms with fixed capacitor compensation and reactive power compensation of STATCOM are corresponding to the changes under different speeds of wind.

From the above figures, the gust wind began at $4 \mathrm{~s}$ and ended at 20 s. When the gust wind is reduced, the voltage keeps decreasing until collapse in the case of fixed capacitor compensation. Voltage comes back to the steady state operation point with STATCOM reactive power compensation. In addition, for STATCOM reactive power compensation, the voltage decrease is much less than the former. Therefore, the reduction of voltage in wind farm is relevant with the lack of reactive power. So the appropriate reactive power compensation can depress voltage fluctuation effectively and improve voltage stability significantly.

2) Simulation analysis of capacitance compensation and static synchronous reactive power compensation under the case of same time and different gust wind

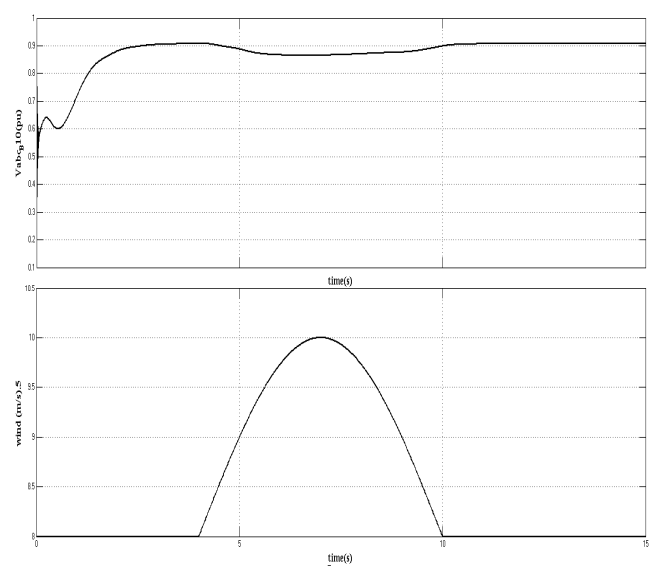

FIGURE IV. GUST WIND SPEED 2M/S

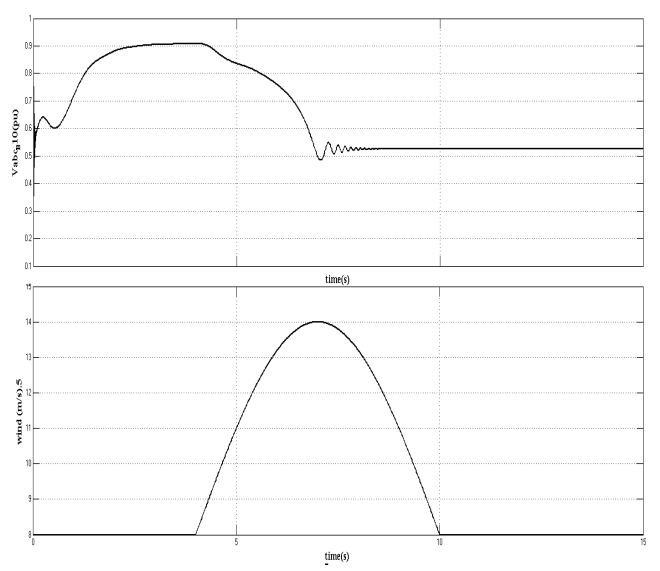

FIGURE V. GUST WIND SPEED 6M/S

Figure 4-5 are the simulation results under ideal condition, where the basic wind speed is $8 \mathrm{~m} / \mathrm{s}$, gust wind strength is 2 $\mathrm{m} / \mathrm{s}$ and $6 \mathrm{~m} / \mathrm{s}$ respectively and duration period is $6 \mathrm{~s}$. The different voltage curves are corresponding to the changes under different wind speed. From these figures, we can see that the 
greater gust wind intensity is, the more intense voltage fluctuation will be. When the gust intensity is $6 \mathrm{~m} / \mathrm{s}$, the voltage of wind farm will continue declining and collapse eventually.

Based on the above simulations about gust wind disturbance, it is shown that under the condition of the same wind strength, the shorter of gust wind lasting duration is, the smaller effect on stability of system voltage is, vice versa. Secondly, under the condition of the same gust wind lasting duration, the greater gust wind strength can make the system stability worse. The voltage collapse induced by gust wind is mainly related to the reactive power of the system. When wind speed is increasing, the active power generation will be increasing, and wind farm needs to absorb more reactive power accordingly. When the system is not able to provide enough reactive power, the wind farm voltage will not recover and become collapsed.

\section{Simulation Case under Ramp Wind}

1) Simulation analysis of basic capacitor compensation and STATCOM reactive power compensation under the case of ramp wind

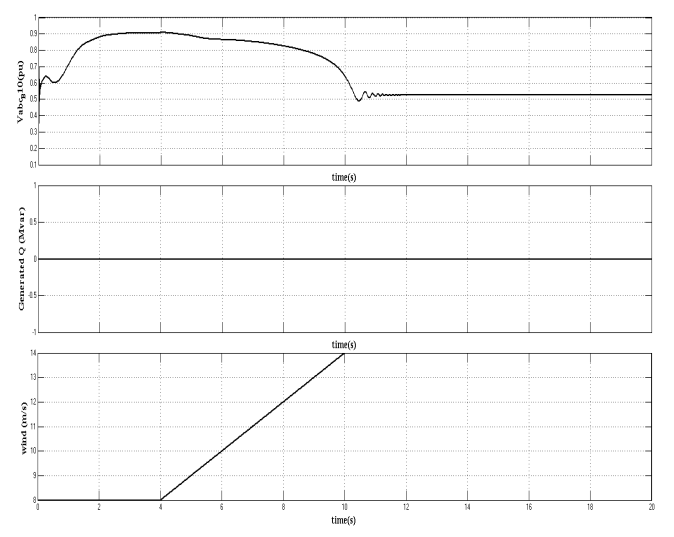

FIGURE VI. WAVEFORM OF CAPACITOR COMPENSATION

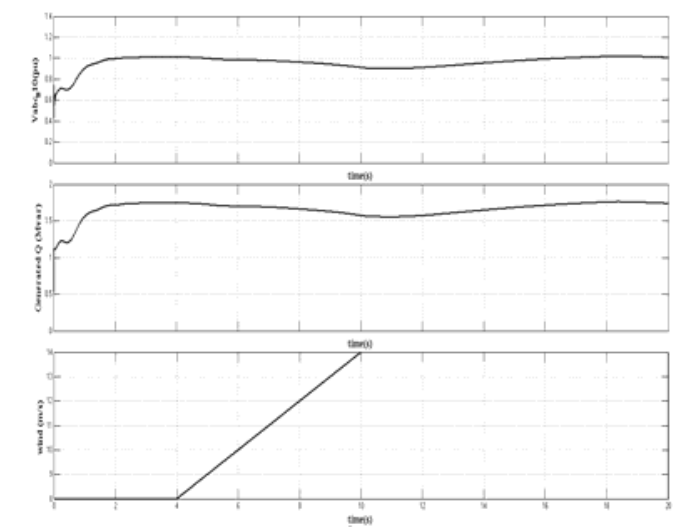

FIGURE VII. WAVEFORM OF STATCOM COMPENSATION

In Figure 6-7, the simulation curve of wind farm on high voltage side under the action of ideal ramp wind is obtained. The ramp wind started at 4 th second and ended at 10th second, its maximum speed is $14 \mathrm{~m} / \mathrm{s}$ and average speed is $8 \mathrm{~m} / \mathrm{s}$ during this period. It is known from the above curves, when the basic wind speed keeps constant, if the wind speed changes gradually and reaches the maximum speed eventually, the voltage with capacitor compensation will collapse while voltage can be recovered to the stable level with STATCOM. From the above analysis, when the same ramp wind occurs, reactive power compensation is different and wind farm operation stability is also different.

\section{CONCLUSIONS}

In this paper, the simulation of wind turbine generator system is carried out, and the voltage stability of wind farm with doubly fed induction generator is analyzed under two kinds of disturbances, the gust wind and the ramp wind. In order to achieve the stability of the voltage, the system is connected with the common capacitor and STATCOM respectively. The following conclusions can be drawn by analyzing their influence on voltage stability.

The greater the gust intensity is, the greater the disturbance to the whole system voltage, and the worse the voltage stability. But for wind farms with variable pitch wind turbine, because the delay effect and regulation of pitch, the longer the duration of wind, with the increase in duration, impact on the voltage stability of the system will be smaller. When the wind intensity is too large, the system may eventually lead to voltage collapse.

When the ramp wind is disturbed, the shorter the duration of wind, the greater the maximum wind speed, that is, the faster the speed of ramp wind, the more detrimental to the stability of the wind farm.

The shortage of reactive power reserve is an important factor causing the unbalance of voltage stability. The proposed method of parallel STATCOM device to provide reactive power compensation on the outlet side of the wind farm is of great significance to maintain the system voltage stability.

\section{REFERENCES}

[1] N. CHEN, L. Z. ZHU, W. WANG, "Wind farm reactive power control strategy for improving voltage stability of access area," Chinese Journal of Electrical Engineering, vol. 10, pp. 102-108, 2009

[2] J. L. LU, S. T. SHI, C. XU, et al. Transient voltage stability analysis of large scale wind farms. Journal of North China Electric Power University (NATURAL SCIENCE EDITION),vol. 1, pp.45-52, 2014

[3] P. ZI, X. X. ZHOU, F. TIAN, et al. Electromechanical transient modeling of doubly fed wind power generator. Chinese Journal of Electrical Engineering, vol.5, pp.1106-1114, 2015

[4] Y. N. CHI, H. L. GUAN, W. S. WANG et al. SVC and pitch control to improve the transient voltage stability of induction generator based wind farm. Power system automation,vol.3, pp.95-100, 2007

[5] S. Q. LI, W. X. XU, W. Z. LI, et al. Voltage control method of DC STATCOM in wind farm. Transactions of China Electrotechnical Society, vol. 3, pp.248-253, 2013

[6] G. F. FAN, Y. L. CHI, H. X. ZHAO et al. Using STATCOM to improve transient voltage stability of wind farm. Transactions of China Electrotechnical Society,vol.11, pp.158-162, 2007

[7] W. X. XU, S. Q. LI, W. Z. LI, et al. Research on voltage stability of grid connected wind farm based on cascaded STATCOM. Journal of Hunan University of Technology, vol.3, pp. 56-60, 2013

[8] P. Y. ZHANG, D. J. WANG, X. L. LIU, et al. Application of H bridge cascaded multilevel STATCOM in wind farm. Power Electronic Technology, vol.8, pp.93-95, 2011 